\section{THE CLINICAL TREATMENT OF SPORTS TO RELIEVE THE DIFFICULTY OF FALLING ASLEEP}

\author{
O TRATAMENTO CLÍNICO DE ESPORTES PARA ALIVIARA DIFICULDADE EM ADORMECER \\ O TRATAMIENTO CLÍNICO DE DEPORTES PARA ALIVIAR LA DIFICULTAD EN DORMIRSE
}

Jing Tang $1 \mathbb{D}$

(Physical Education Professional)

1. Physical Education Institute of Xi'an, Peihua University, Shaanxi, China.

\section{Correspondence}

Jing Tang

Shaanxi, China, 710000.

tj781212abc@163.com

\begin{abstract}
Introduction: Difficulty falling asleep is connected to the malfunctioning of the sleep and wakefulness mechanism of the human body caused by various reasons. There are a series of adverse reactions resulting from abnormal or poor quality of sleep during sleep per se. This symptom severely affects an individual's physical condition and mental health. Objective: To explore the effect of physical exercise on patients with difficulty falling asleep. Methods: Mathematical statistics were used to analyze 60 patients with difficulty falling asleep. We divided the patients into a sports group and a control group. The patients in the sports group took sports training, while the control group did not. After two weeks of intervention and comparison, we used mathematical statistics to evaluate the groups' cognitive function. Results: After physical exercise, the patient's sleep quality was higher and sleep disorders were reduced. Conclusion: Physical activity is a simple and popular way of exercising. It is effective in improving the cognitive function of patients with difficulty falling asleep. Level of evidence Il; Therapeutic studies - investigation of treatment results.
\end{abstract}

Keywords: Sleep Wake Disorders; Sports; Cognition; Clinical Protocols.

\section{RESUMO}

Introdução: A dificuldade em adormecer está ligada ao mau funcionamento do mecanismo do ciclo sono-vigília no corpo humano eé causada por diversos motivos. Existe uma serie de reações adversas que resultam da má qualidade - ou qualidade anormal - do sono, especificamente durante o sono. Esses sintomas afetam seriamente a condição física e a saúde mental das pessoas. Objetivo: Explorar o efeito de exercícios físicos em pacientes com dificuldade em adormecer. Métodos: Estatísticas matemáticas foram usadas para analisar 60 pacientes com dificuldade em adormecer. Dividimos os pacientes em um grupo de esportes e outro de controle. Os pacientes no grupo de esportes tiveram treinamento esportivo, enquanto o grupo de controle não. Após duas semanas de intervenção e comparação, usamos estatísticas matemáticas para avaliar a função cognitiva dos grupos. Resultados: Após o exercício físico, houve melhora na qualidade de sono dos pacientes e os transtornos do sono diminuíram. Conclusão: A atividade física é uma forma simples e popular de se exercitar. É eficaz na melhora da função cognitiva de pacientes com dificuldade de adormecer. Nível de evidência Il; Estudos terapêuticos - investigação de resultados de tratamento.

Descritores: Transtornos da Transição Sono-Vigília; Esportes; Cognição; Protocolos clínicos.

\section{RESUMEN}

Introducción: La dificultad en dormirse se relaciona al mal funcionamiento del mecanismo del ciclo sueño-vigilia en el cuerpo humano y es causada por diversos motivos. Existe una serie de reacciones adversas que resultan de la mala calidad o calidad anormal del sueño, durante el sueño en sí. Esos síntomas afectan seriamente la condición física y la salud mental de las personas. Objetivo: Explorar el efecto de ejercicios físicos en pacientes con dificultad en dormirse. Métodos: Dividimos los pacientes en un grupo de deportes y otro de control. Los pacientes en el grupo de deportes tuvieron entrenamiento deportivo, mientras el grupo de control no. Tras dos semanas de intervención y comparación, usamos estadísticas matemáticas para evaluar la función cognitiva de los grupos. Resultados: Tras el ejercicio físico, hubo mejoría en la calidad del sueño de los pacientes y los trastornos del sueño disminuyeron. Conclusión: La actividad física es una forma simple y popular de ejercitarse. Es eficaz en la mejoría de la función cognitiva de pacientes con dificultad de dormirse. Nivel de evidencia ll; Estudios terapéuticos - investigación de resultados de tratamiento.

Descriptores: Trastornos de la Transición Sueño-Vigilia; Deportes; Cognición; Protocolos clínicos.

\section{INTRODUCTION}

Difficulty falling asleep refers to the malfunction of the body's sleep and wakefulness mechanism caused by various reasons. This is a series of adverse reactions caused by the abnormal or poor quality of sleep during sleep. This symptom severely affects the physical condition and mental health of the individual. The study found that the incidence of sleep disorders among college students was 13\%. Event-related potential (ERP) refers to the brain potential that can be recorded from the surface of the head when a person performs cognitive processing (such as attention, memory, thinking) on an object. P300 is an ERP component related to 
cognitive functions such as attention, recognition, and decision-making. It is a "window for observing brain function" and is now widely used in the field of cognitive neuroscience.' Several studies have pointed out that sleep disorders will affect the changes in the cognitive potential of the cerebral cortex of college students, leading to varying degrees of impairment of cognitive function. Some scholars have shown that jogging can promote deep sleep, which can effectively improve the sleep quality of college students and reduce the symptoms of sleep disorders. Reviewing the literature, it is known that there is no research on the effect of jogging on the event-related potential P300 of sleep disorders in the intervention studies of sleep disorders in college students. ${ }^{2}$ In view of this, this study used event-related potential P300 to verify the effect of jogging on the cognitive function of students with sleep disorders, to provide an objective basis for improving the quality of sleep-in college students.

\section{METHOD}

\section{Object}

From January to June 2019, we used convenient sampling to randomly distribute promotional materials throughout the medical school. We conduct the Pittsburgh Sleep Quality Index (PSQI) test on full-time college students who perceive poor sleep quality. At the same time, 60 students with PSQI score $\geq 8$ points are selected as the research objects. Inclusion criteria: 1) All are primary sleep disorders. 2) Exclude patients with sleep disorders caused by mental disorders, physical diseases, and drug abuse. 3) Volunteer to participate in this study and sign an informed consent form. Among them, 32 were males and 28 were females, with an average age of (20.16 \pm 1.37 ) years old. ${ }^{3}$ The article uses a random number table method to divide the study subjects into a control group and an intervention group of 30 each. There was no statistically significant difference in gender and age between the two groups (all P>0.05), and they were comparable.

\section{Research methods}

\section{Intervention methods}

1) The intervention group performed jogging training during the experiment. Training method: Volunteers start jogging every evening from 7:30 to 8:00, each time lasts 50 minutes, and they train for 2 weeks. In order to ensure that the members of the intervention group can perform jogging training on time, the researchers handed out small gifts to the study subjects and established a jogging training diary. We require them to record the start and end time of each jogging, the start and end time of sleep, and their feelings to facilitate researchers to understand the compliance of the research subjects in time and ensure the quality of intervention. 2) The daily behavior and lifestyle of the control group remained unchanged during the test period. ${ }^{4}$ We do not carry out any intervention measures on it.

\section{Evaluation method}

1) Sleep quality: We use the Pittsburgh Sleep Quality Index (PSQI) measurement. PSQI is compiled by Buysse et al. The PSQI consists of 19 self-rated items and 5 other-rated items. The total score ranges from 0 to 21 points. We use PSQI $\geq 8$ as the criterion for judging sleep quality problems. The higher the score, the worse the quality of sleep. ${ }^{5}$ PSQI has good reliability and validity, and it can be used to comprehensively evaluate the sleep quality of patients with sleep disorders. 2) The objective evaluation of event-related potential P300 on cognitive function. We use a 32-lead EEG evoked potential meter produced by Brain Products, Germany, and Brain Vision Pycorder software to record brain waves synchronously. The experiment uses Brain Vision Analyzer 2.1 software for offline data analysis. The recording electrodes are placed in the center $(\mathrm{Cz})$ and the top $(\mathrm{Pz})$ respectively. The reference electrode is a bilateral mastoid, the ground electrode is the center of the forehead, and the ground electrode impedance is less than $5 \Omega$. We use the Oddball auditory paradigm for EEG recording. ${ }^{6}$ This mode consists of two different tones of stimuli randomly compiled into a stimulus sequence. The target stimulus is a pure tone of $2000 \mathrm{~Hz}, 90 \mathrm{~dB}$, and an appearance frequency of $15 \%$. The non-target stimulus is $1000 \mathrm{~Hz}, 85 \mathrm{~dB}$ pure tone. The frequency of occurrence is $85 \%$, and the stimulation interval is $1.5 \mathrm{~s}$. Before the test, inform the research object of the purpose and requirements, and explain the action method of the instrument and the conductive paste. During the test, the subjects were asked to stay awake, relaxed, close their eyes and concentrate.? When the target stimulus audio appears, the subject is required to press the space bar quickly, while the non-target stimulus does not respond. The experiment was conducted in the laboratory of the School of Nursing, Medical College. The sound insulation effect is good here, and the light is dim. It can avoid interference factors.

\section{Feature extraction of brain wave signal}

This article attempts to extract the EEG signals of $\alpha, \beta, \delta, \theta$ and four rhythms based on wavelet packet decomposition. ${ }^{8}$ Considering the frequency ranges of the four EEG rhythms, we apply 8-layer wavelet packet decomposition to EEG signals according to the Nyquist theorem. The following wavelet packet base can be constructed:

$$
\varphi^{2 i}{ }_{j, k}(t)=\frac{1}{\sqrt{2}} \varphi^{2 i}\left(\frac{2^{j} k-1}{2^{j}}\right)=\sum_{n} h(n) \varphi_{j-1,2 k-n}^{i}(t)
$$

$$
\varphi_{j, k}^{2 i+1}(t)=\frac{1}{\sqrt{2}} \varphi^{2 i+1}\left(\frac{2^{j} k-1}{2^{j}}\right)=\sum_{n} g(n) \varphi_{j-1,2 k-n}^{i}(t)
$$

$h(n)$ and $g(n)=(-1)^{1-n} h(1-n)$ are a pair of orthogonal mirror filters. ${ }^{9}$ The point $k$ can be expressed by the following recursive formula:

$d^{2 i}{ }_{j}(k)=\int f(t) \varphi_{j, k}^{2 i}(t) d t=\sum h(n) d^{i}{ }_{j-1}(2 k-n)$

The reconstructed signal can be expressed as:

$$
f(t)=\sum_{i=0}^{2^{i}-1} \sum_{k=0}^{m \cdot 2^{N-1}-1} d_{j}^{2 i}(k) \varphi_{j, k}^{2 i}(t)+\sum_{i=0}^{2^{i}-1} \sum_{k=0}^{m \cdot 2^{N-1}-1} d_{j}^{2 i+1}(k) \varphi_{j, k}^{2 i+1}(t)
$$

\section{Statistical methods}

We used SPSS20.0 statistical software to perform statistical analysis on the latency and volatility of P300 before intervention and two weeks after intervention. The measurement data is represented by $(\bar{x} \pm s)$. The data conforms to the normal distribution. ${ }^{10}$ We use t test, and $\mathrm{P}<0.05$ as the difference is statistically significant.

\section{RESULTS}

PSQI assessment results before and after intervention in the 2 groups

The comparison results showed that the sleep quality, daytime function, and sleep quality index of the intervention group were significantly improved compared with the control group, the sleep efficiency was significantly improved, and the sleep disorder condition was significantly improved $(P<0.05$ or $P<0.01)$. (Table 1)

\section{Comparison of P300 latency and volatility before and after the intervention of the two groups}

Compared with the control group, the incubation period of the $\mathrm{Pz}$ and $C z$ sites in the intervention group was significantly shortened after the intervention, and the amplitude was significantly increased $(P<0.01)$. 
The incubation period of the $\mathrm{Pz}$ and $\mathrm{C} z$ sites in the intervention group was shortened before and after the intervention, and the volatility increased $(P<0.01)$. (Table 2$)$

Table 1. Comparison of PSQI evaluation results before and after intervention in the two groups $(\bar{x} \pm s)$

\begin{tabular}{c|c|c|c|c}
\hline & \multicolumn{2}{|c|}{ Intervention group $(\mathbf{n}=\mathbf{3 0})$} & \multicolumn{2}{c}{ Control group $(\mathbf{n}=\mathbf{3 0})$} \\
\hline \multirow{2}{*}{ Index } & $\begin{array}{c}\text { Before } \\
\text { intervention }\end{array}$ & $\begin{array}{c}\text { After the } \\
\text { intervention }\end{array}$ & $\begin{array}{c}\text { Before } \\
\text { intervention }\end{array}$ & $\begin{array}{c}\text { After the } \\
\text { intervention }\end{array}$ \\
\hline Sleep quality & $2.03 \pm 0.49$ & $1.27 \pm 0.45$ & $1.90 \pm 0.61$ & $1.80 \pm 0.66$ \\
\hline Time to fall asleep & $2.03 \pm 0.61$ & $1.47 \pm 0.68$ & $1.97 \pm 0.56$ & $1.80 \pm 0.55$ \\
\hline sleeping time & $1.37 \pm 0.49$ & $0.97 \pm 0.61$ & $1.37 \pm 0.49$ & $1.20+0.41$ \\
\hline Sleep efficiency & $0.87 \pm 0.82$ & $0.47 \pm 0.51$ & $0.83 \pm 0.83$ & $0.83 \pm 0.75$ \\
\hline sleep disorder & $1.20 \pm 0.41$ & $0.93 \pm 0.45$ & $1.37 \pm 0.49$ & $1.33 \pm 0.48$ \\
\hline Hypnotics & - & - & - & - \\
\hline Daytime function & $2.63 \pm 0.56$ & $1.90 \pm 0.48$ & $2.53 \pm 0.57$ & $2.40 \pm 0.56$ \\
\hline PSQI & $10.13 \pm 1.48$ & $7.00 \pm 1.49$ & $9.97 \pm 1.69$ & $9.37 \pm 1.42$ \\
\hline
\end{tabular}

Table 2. Comparison of P300 latency and volatility before and after intervention in the two groups $(\bar{x} \pm s)$

\begin{tabular}{|c|c|c|c|c|}
\hline Group & Time & $\begin{array}{l}\text { Number } \\
\text { of cases }\end{array}$ & PzL(ms) & $\mathrm{CzL}(\mathrm{ms})$ \\
\hline \multirow{3}{*}{ Intervention group } & $\begin{array}{c}\text { Before } \\
\text { intervention }\end{array}$ & 30 & $345.70 \pm 24.29$ & $345.53 \pm 22.75$ \\
\hline & $\begin{array}{c}\text { After the } \\
\text { intervention }\end{array}$ & 30 & $284.97 \pm 19.62$ & $286.00 \pm 20.64$ \\
\hline & $\mathrm{t} / \mathrm{Z}$ & & 15.098 & 14.491 \\
\hline \multirow{3}{*}{ Control group } & $\begin{array}{c}\text { Before } \\
\text { intervention }\end{array}$ & 30 & $342.90 \pm 20.49$ & $341.60 \pm 21.44$ \\
\hline & $\begin{array}{l}\text { After the } \\
\text { intervention }\end{array}$ & 30 & $344.07 \pm 18.87$ & $340.97 \pm 21.13$ \\
\hline & $\mathrm{t} / \mathrm{Z}$ & & -0.45 & 0.433 \\
\hline $\begin{array}{c}\text { Comparison of } 2 \text { groups } \\
\text { after intervention }\end{array}$ & $t / Z$ & & -11.546 & -10.597 \\
\hline Group & time & $\begin{array}{l}\text { Number } \\
\text { of cases }\end{array}$ & $\operatorname{PzA}(u V)$ & $\mathrm{CzA}(\mathrm{uV})$ \\
\hline \multirow{3}{*}{ Intervention group } & $\begin{array}{c}\text { Before } \\
\text { intervention }\end{array}$ & 30 & $12.38 \pm 1.99$ & $13.17 \pm 1.76$ \\
\hline & $\begin{array}{c}\text { After the } \\
\text { intervention }\end{array}$ & 30 & $14.97 \pm 2.01$ & $15.72 \pm 2.10$ \\
\hline & $\mathrm{t} / \mathrm{Z}$ & & -7.234 & -6.54 \\
\hline \multirow{3}{*}{ Control group } & $\begin{array}{c}\text { Before } \\
\text { intervention }\end{array}$ & 30 & $12.50 \pm 2.04$ & $13.16 \pm 1.85$ \\
\hline & $\begin{array}{l}\text { After the } \\
\text { intervention }\end{array}$ & 30 & $12.31 \pm 1.81$ & $13.49 \pm 1.81$ \\
\hline & $\mathrm{t} / \mathrm{Z}$ & & 1.404 & -1.203 \\
\hline $\begin{array}{c}\text { Comparison of } 2 \text { groups } \\
\text { after intervention }\end{array}$ & $t / Z$ & & 4.474 & 5.437 \\
\hline
\end{tabular}

\section{DISCUSSION}

\section{Jogging can improve sleep quality}

This group of studies showed that compared with the control group, the intervention group's sleep quality, daytime function and sleep quality index significantly improved, sleep efficiency improved, and sleep disorders improved significantly. This shows that jogging can effectively improve the sleep quality of college students. The reason for the analysis may be that jogging can cause the body to produce moderate fatigue. It consumes too much energy, reduces excitability, and can help shorten the time to fall asleep, thereby deepening sleep depth and reducing sleep disorders. Jogging can regulate biological rhythms and improve the function of the nervous system to promote the body's production of endorphins. As a sedative, endorphins can effectively help people reduce stress, relieve stress, and eliminate the vicious circle of anxiety, depression, and other bad moods on sleep quality.

\section{The effect of jogging on event-related potential P300}

This study found that compared with the control group, the incubation period of the $\mathrm{Pz}$ and $\mathrm{Cz}$ sites in the intervention group was significantly shortened after the intervention, and the volatility was significantly increased. In the intervention group, the incubation period of Pz and $\mathrm{Cz}$ sites was shortened and the volatility increased before and after the intervention. Jogging can shorten the incubation period of the subjects and increase the volatility. The amplitude of event-related potential P300 reflects the brain's ability to perceive target stimuli and the extent of effective resource utilization during information processing, which is related to the intensity of attention, memory, and cognitive processing. The latency of P300 reflects the speed at which the brain recognizes and processes target stimuli. It includes perception, attention, memory, information coding ability, abstract induction ability, thinking transfer ability, cognitive processing speed, executive function, etc. This can reflect the overall level of brain function to a certain extent.

\section{CONCLUSION}

This study uses event-related potential technology to verify the effect of jogging on the cognitive function of college students with sleep disorders. This provides an objective basis for jogging to improve the cognitive function of college students with sleep disorders and improve the quality of sleep of college students. Jogging, as a simple and popular way of exercise, has operability in improving the cognitive function of college students with sleep disorders. This is easy to be promoted and used. However, due to the small sample size in this study, the research objects could not be stratified. We found that there are limitations in the selection of subjects in this study and the intervention time is short, so it is impossible to discuss the long-term effects of jogging intervention. In future research, we should expand the sample size and extend the intervention time. Our application should more systematically and accurately explore the mechanism of jogging on improving the cognitive function of college students with sleep disorders.

The author declare no potential conflict of interest related to this article

\section{REFERENCES}

1. Howell DR, Oldham JR, Brilliant AN, Meehan WP 3rd. Trouble falling asleep after concussion is associated with higher symptom burden among children and adolescents. J Child Neurol. 2019 Apr;34(5):256-261.

2. Anderson M, Petit KM, Bretzin AC, Elbin RJ, Stephenson KL, Covassin T. Sport Concussion Assessment Tool Symptom Inventory: Healthy and Acute Postconcussion Symptom Factor Structures. J Athl Train. 2020 Oct 1;55(10):1046-1053

3. Eagle SR, Kissinger-Knox AM, Womble M, Elbin RJ, Feder A Kegel N, Collins M, et al. A-07 PostConcussion symptom scale factors shift with longer time since injury in adolescents with sport-related concussion. Arch Clin Neuropsychol. 2021;36(4);647.

4. Moser RS, Olek L, Schatz P. Gender differences in symptom reporting on baseline sport concussion testing across the youth age span. Arch Clin Neuropsychol. 2019;34(1):50-9.

5. Carling C, Leprince C, Pavillon T, Guétin S, Thivilier F. Feasibility and effectiveness of a novel smartphone music application on anxiety and sleep in elite soccer coaches. J Sports Sci Med. 2021;20(3):546-7.

6. Kunorozva L, Viviers P, Derman W, Brown J. Presenting features of female collegiate sports-related concussion in South Africa: a descriptive analysis. SA J Sports Med. 2021;33(1);1-7.

7. Montagni I, Vialemaringe $M$, Tzourio $C$. Sport practice and perceptions in university students: a mixed-methods study. Uluslararası Spor Bilimleri Öğrenci Çalışmaları. 2020;2(1);1-15.

8. Blake AL, McVicar CL, Retino M, Hall EE, Ketcham CJ. Concussion history influences sleep disturbances, symptoms, and quality of life in collegiate student-athletes. Sleep Health. 2019 Feb;5(1):72-77.

9. Black AM, Miutz LN, Kv VW, Schneider KJ, Yeates KO, Emery CA. Baseline performance of high school rugby players on the sport concussion assessment tool 5. J Athl Train. 2020;55(2):116-123.

10. Murphy CJ, Mason BS, Goosey-Tolfrey VL. Exercise Recovery Practices of Wheelchair Court Sports Athletes. J Strength Cond Res. 2021;35(2):366-72. 